\title{
Upper canines and incisors: how a better knowledge of their morphology can help us to optimise their function
}

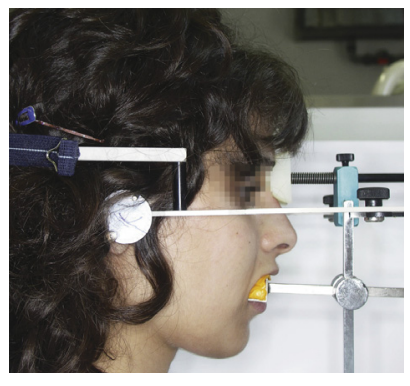

\author{
Amine EL ZOGHBY, Jean-Philippe RÉ, Christophe PEREZ, \\ Anne GIRAUDEAU, Jean-Daniel ORTHLIEB
}

Address for correspondence:

A. EL ZOGHBY,

rue de Damas,

B.P. $11-5076$

Riad el-Solh

11072180 Beyrouth

Liban.

elnamina@sodetel.net.lb

\section{ABSTRACT}

Biometric study of contemporary human maxillary incisors and canine coronal morphology

The orthodontic alignment or prosthetic rehabilitation of the upper anterior sector is based on available biometric data.

The aim of this study is to measure the angle formed between the functional lingual surface of the canine and central incisor and the axial-orbital plane.

\section{Materials and methods}

This retrospective study is based on an analysis of documents of young dental students.

The measurements were made on 49 silicone models of healthy, natural, functional teeth, in class I occlusion for the maxillary anterior group.

\section{Results}

The values of slope angulations of the lingual surfaces relative to the axial-orbital plane clearly decrease by $10^{\circ}$ from the central incisor $\left(57^{\circ}\right)$ to the canine $\left(47^{\circ}\right)$.

If there is stability in buccal morphology, there is variability in anterior lingual morphology, particularly of the canine.

These variations in an essential zone on the functional level are marked enough to warrant being taken into account in clinical practice.

\section{KEYWORDS}

Biometric

Incisal guidance

Canine guidance

Coronal morphology

Incisor

Canine. 


\section{1 - BIOMETRIC STUDY OF THE CORONAL MORPHOLOGY OF UPPER INCISORS AND CANINES IN MODERN HUMANS}

\section{1 - 1 - Introduction}

Fifteen years ago, an emeritus clinician, Harold Shavell22 wrote: "In a stable occlusion (inter-arch intercuspation) dental treatment must reflect absolute and faultless submission to the morphological structural data. Morphology is the destiny of dentistry."

Dentists often use specific devices and protocols to reposition or rehabilitate the maxillary anterior teeth in order to improve their achieving aesthetic alignment. Although the labial surfaces of these teeth usually display similar convex shapes, the lingual morphology of the upper incisors and canines varies greatly (fig. 1 and 2 ). And it is

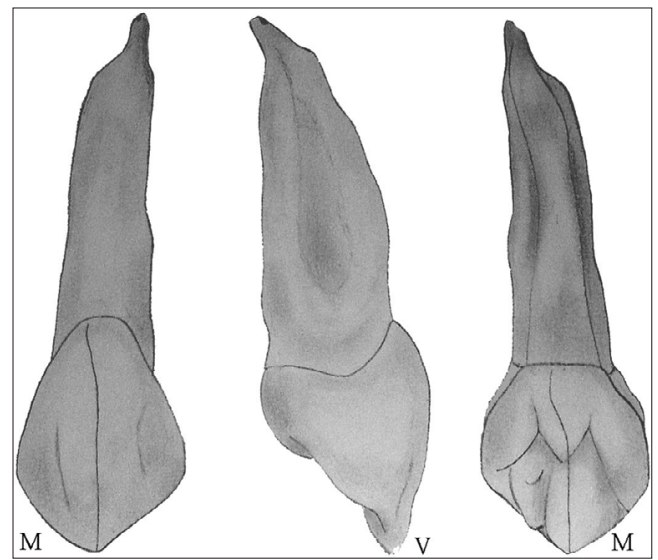

Figure 1

Upper left upper: labial, mesial and lingual views. The position in space and slope of genetically predetermined dental morphology will influence mandibular aesthetics and kinematics. precisely these lingual surfaces that play an essential role in masticatory function8.

\section{1 - 2 - Morphology induces the occlusal guidance function}

Very often, orthodontists set and achieve a goal in treatment of adults of altering anterior guidance function. While as yet there is no formal proof of its efficacy, dentists usually establish a therapeutic plan designed to achieve immediate posterior disocclusion in mandibular translation movements. This total disocclusion, which is scarcely physiological but easy for

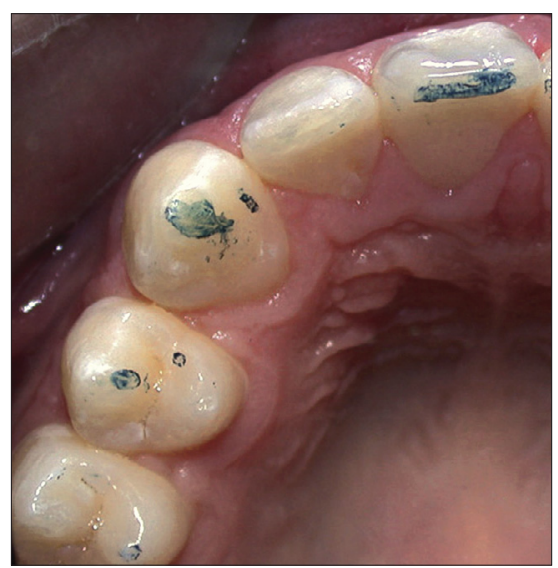

Figure 2

An inspection of its facial surface alone can not provide any information about a tooth's lingual morphology. 
dentists to obtain technically, is quite opposed to the notion of a balanced "equilibrated" occlusion that would be characterised by the simultaneous presence of anterior and posterior occlusal contacts in mandibular propulsive and lateral excursion movements 5 .

Because no one has so far presented adequate scientific evidence to show which is most effective, dentists have to rely on clinical conclusions and the scanty factual data now available, to establish their treatment plans. But there is general agreement among practitioners working in the field that a canine protected occlusion may be the most acceptable as Rinchuse et al., reported in a review that found the literature to be replete with sectarian and rather vague conclusions ${ }^{19}$. We feel, therefore, it is essential for us to explain why we believe the therapeutic design of canine protection appears to be valid:

- the therapeutic creation of canine function through orthodontics or prosthetic treatment is easier to obtain than group function;

- a pathogenic outcome of canine protection has never been shown, but the case for posterior occlusal interference leading to harmful effects seems much more likely.

We want to make it clear that our belief in the therapeutic value of canine guidance is only an opinion. In view of the fragile nature of the available scientific data ${ }^{17}$, no reasonable person could dignify an interpretation of the status of the debate on group, canine, or any occlusal function as something more solid than that; it is just an opinion.

Mandibular kinematics depends on the functioning of occlusal guidance. In the last phase of excursive movement, the tooth guidance surfaces pilot the developing mandibular elevation by anticipation, rather in the way of an access cone moving directly towards a target which is maximal intercuspation in occlusion (MIO). This target must be accurate and unique. This guidance avoids obstacles Into a position of maximal inter-cuspation, in the way an access cone gives a path to a target. This occlusal target must be precise and unique, avoiding occlusal obstacles. It is essential that we understand what is meant by "occlusal interference", guidance surfaces, and occlusal contacts.

- Occlusal interference is defined as dental obstacles generating limitation and/or deviation of horizontal mandibular trajectories in propulsive or lateral excursions ${ }^{15}$

- Posterior occlusal interference is characterised during a propulsive or lateral excursion translation movement by occlusal contact on a multicusp tooth without simultaneous anterior occlusal contact. In other words, "a posterior tooth releases the anterior teeth during translation" 10 .

Remarks concerning group function: Guidance only by the canine (canine function) or with the participation of other teeth contiguous to the canine (more or less extensive group function) are functional guides, because there is no interference. Group function is a form of guidance which is effective in mastication at the cost of eroding tooth surfaces.

- Anterior occlusal interference might be thought of as over guidance, blocking mandibular translation. In a propulsion movement, isolated con- 
tact on the mandibular teeth must move in accordance with the linear trajectories on the maxillary guidance surfaces. Anterior interference results from an excessively vertical guidance slope. It is revealed by the presence of reversed guidance zones: linear on the labial surfaces of the mandibular incisors or canines and at discrete points on the maxillary anterior teeth.

By promoting simple, direct movements, the slight predominance of anterior contacts facilitates neuromuscular action 25 while minimizing erosion of enamel. From the mastication point of view, harmonious occlusal curves and dominant but mild canine slopes promote homogeneous, symmetrical contact between the occlusal tables and optimise grinding of foodstuffs. In parafunctional activities like bruxism and gum chewing, during lateral excursion the proximity of antagonistic posterior occlusal tables acts as an occlusal parapet, protecting the TMJs during strong activation of the elevators. On the other hand, where canine guidance is overly steep, this protection is absent and the anterior blockage it causes will prevent translation movements which generate mandibular retro-function and/or lateral function. This makes the mandible operate in opposition to the natural direction of anatomico-physiological function of the Temporomandibular joints (TMJ).

This proprioceptive guidance, working by anticipation, depends on the organization of the anterior teeth which display architectural and morphological aspects specific to our human lineage ${ }^{14}$. The lack of premature wear in the dental system in modern populations accentuates the functional role played by dental morphology 21 .

\section{1 - 3 - Reference plane}

Any evaluation of occlusal functions requires a non-dental horizontal baseline. The traditional anthropological reference, the Frankfurt plane, accepted at the International Anthropology Conference at Frankfurt in 1884, is a plane in bone passing through the Porions (upper edge of the external auditory

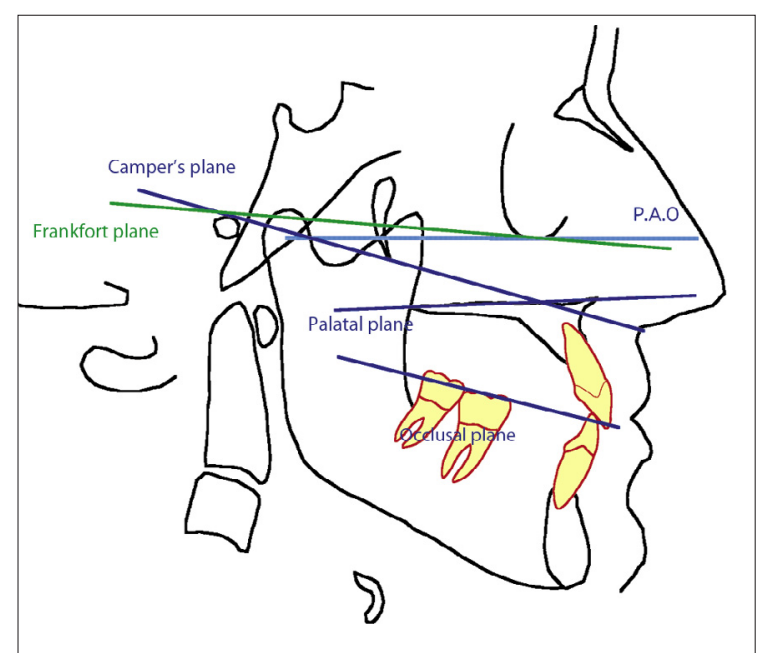

Figure 3

The different reference planes in sagittal view

meatus) and left infraorbital point. It corresponds to the position of the head of a person looking at the horizon, in an orthostatic position. Clinically, dentists use a cutaneous Frankfurt plane defined as passing through the Tragions (upper edge of the tragus) and the left cutaneous Infraorbital point (antero-inferior edge of the orbit) ${ }^{15}$. 
It is a common error to think that the Frankfurt plane is the horizontal reference plane for mounting models on articulators, particularly when a transfer arch with auricular end-piece is used. In fact, the great majority of articulator systems employ the AxialOrbital Plane (AOP), directly or by approximation.

It passes through the Condylicus points (cutaneous or bony) and the left Infraorbital point ${ }^{3}$. The posterior reference is, indeed, at the level of the bi-condylar rotation axis (this detail was provided by Mc Collum in 1924 and Stuart in 195518. The mean differential angle (fig. 3) between the Frankfurt plane and the AOP is around $7^{\circ}$ (Standard deviation $2^{\circ}$ out of 46 measurements) ${ }^{16}$.

Data can be superposed and duplicated on different articulators with the AOP, as well as in cephalometric analyses and axiographic recordings. The AOP also provides a set-up of dental arches which are spatially correct or at least close to the horizontal baseline linked to the semi-circular canals 4 .

\section{1 - 4 - The variability of dental morphology}

During the life of the natural dentition, the guidance slope adapts it to environmental pressures and compensates for skeletal deviations, even though nature dictates tooth morphology. The lingual morphology of maxillary anterior teeth clearly plays a major part in guidance function through the location of anatomical relief6,12,24. Accordingly, orthodontists should evaluate the extent of the pre-determined labio-lingual inclination of the lingual convexities of upper anterior teeth during treatment.

Many statistical studies using cephalometry on the bucco-lingual slopes of the incisors have provided reference data which orthodontists can use to obtain optimal axial positioning of teeth in conformity with skeletal types and aesthetic criteria.

In assessing tooth morphology orthodontists can refer to dental anatomy manuals that give an academic reference model for each type of tooth. But these models are only generalisations that do not take individual differentiations into account. The biometric data in the literature on the morphology of modern human upper anterior teeth is scanty and what there is applies primarily to incisors ${ }^{11}$. Both common sense and available studies caution us, as is the case for all biological data, that variation between individuals is great, and, for anterior teeth is concentrated in the functional zone, the lingual surfaces.

So we have decided it would be useful to study the morphological variability of upper incisor and canine crowns to derive a theoretical set of mean values that could help orthodontists to decide whether each clinical situation requires a customised individual plan or whether they can use mean values to treat specific cases.

This study proposes to furnish biometric, quantitative bucco-lingual data about anterior-maxillary teeth, by comparing the morphology of the upper central incisor and canine teeth of a group of modern humans. 


\section{2 - MATERIALS AND METHOD}

\section{2 - 1 - Sample}

This is a retrospective study of educational documents including information obtained during the initial dental student clinical training period. In their program dental students fill out questionnaires, examine each other clinically, take impressions of each other's teeth, and prepare morphological analyses of their teeth in relation to a horizontal reference plane derived from a face bow. We accumulated our data by analysing the data provided by the questionnaires and the clinical examination reports. We selected 49 consecutive files of 27 male and 22 female students whose average age was 22.

Criteria for selection:

- young subjects between 22 and 25 years of age whose teeth would not yet have suffered much dental erosion;

- natural healthy dental arches;

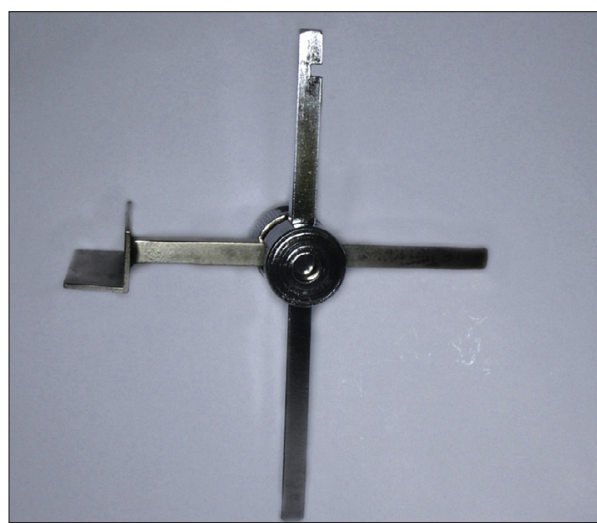

Figure 4

Orthogonal support - class I Angle occlusion with anterior contacts at maximal intercuspation.
- class I Angle occlusion with anterior contacts at maximal intercuspation.

Criteria for exclusion from the study:

- history of dysfunction of the masticatory apparatus;

- orthodontic treatment in progress or completed;

- dental reconstruction of the lingual part of an anterior tooth;

- significant malocclusion;

- guidance anomaly: posterior interference, anterior open bite.

\section{2 - 2 - Method}

For each subject, we constructed a silicone model of the upper anterior teeth mounted correctly in space on the articulator by means of an ear-bow arbitrary face-bow transfer instrument whose horizontal and frontal positioning we checked clinically as we proceeded. By means of a right angle

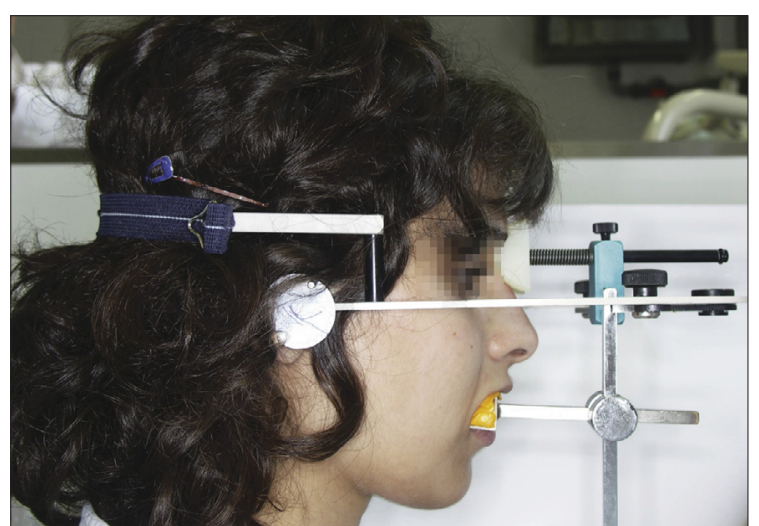

Figure 5

The orthogonal support, lined with silicone, fixed to the Quick ${ }^{\circledR}$ Axiograph, records the morphology of the anterior-maxillary teeth referenced in the Axial-orbital plane. 


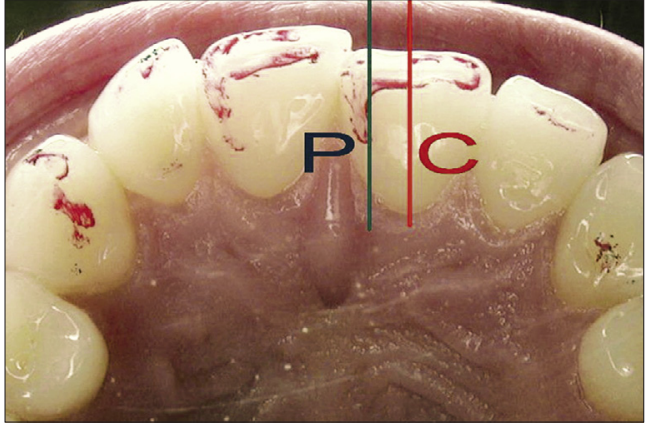

Figure 6

Location of section illustrated of an upper left central incisor: Central section $(C)$ and proximal section $(P)$.

support to the transfer arch plane we registed the horizontal reference plane, the Axio Orbital plane, and at the same time the morphology of the upper anterior group of teeth (fig. 4 and 5). In this way the modeling can be done directly in the mouth with a silicone elastomere key (Elite ${ }^{\circledR}$ $\mathrm{H}-\mathrm{D}+$.Zhermack).

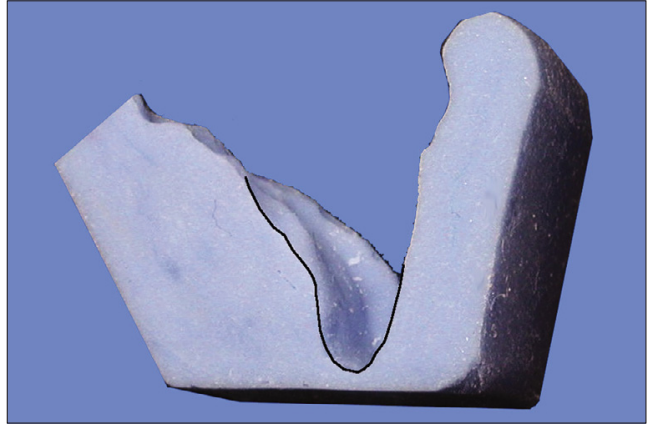

Figure 7

Vertical, orthogonal sections are cut along the previously defined cutting levels.

Each silicone core is sectioned perpendicular to e reference plane at two levels for each canine and central incisor (fig. 6). The sections are in the middle of the tooth (central section C) and at the main point of contact in maximum intercuspation occlusion (MIO), usually on a proximal crest (Proximal section - P).

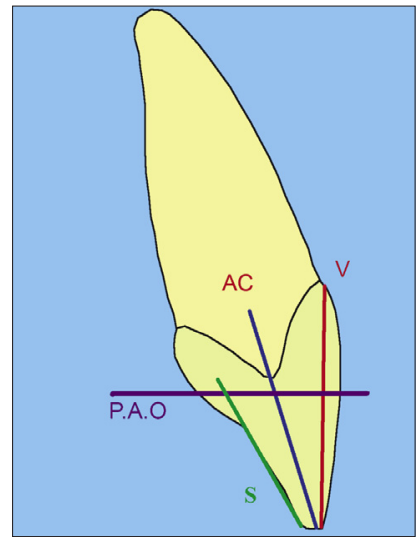

Figure 8

Definition of labio-lingual biometric parameters: ( $S$ : lingual slope, $V$ : vestibular slope, AC: coronal axis, AOP: transposition of the Axial-orbital plane).

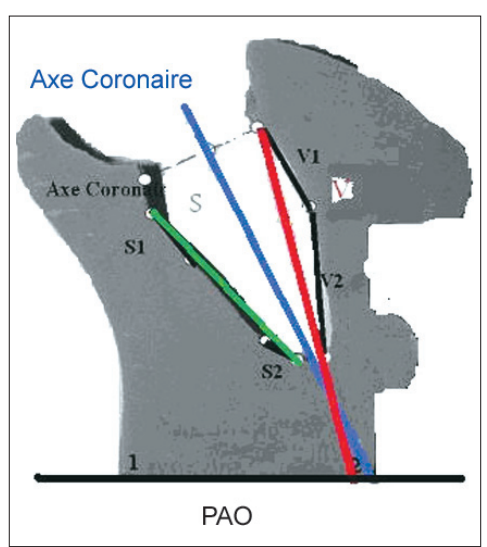

Figure 9

Each section of the silicone core is numbered the lower part of the silicone represents the reference plane and the 10 $\mathrm{mm}$ scale). The biometric parameters will be quantified on each section.

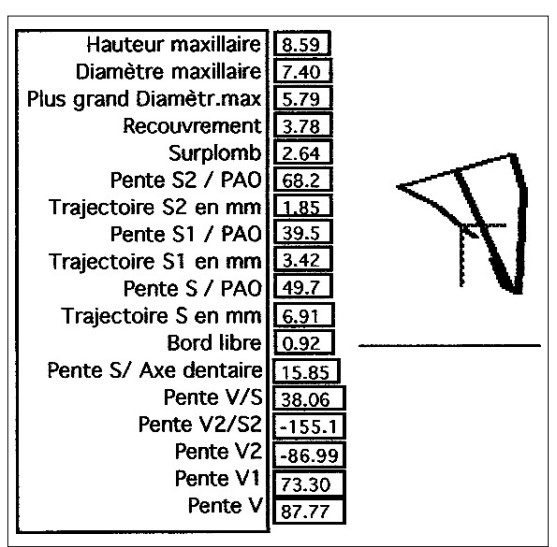

Figure 10

Screen view obtained after entering the details of a proximal section of a 21 (all the values are expressed in degrees or millimetres). 
The different sections are numbered by standard photographs then quantified using software specially developed for the purpose (fig. 9). The reference dimension is given by the length of the impression fork support.
The slopes between the different axes are evaluated relative to the anatomical points noted (fig. 8 and 9) (labial and lingual cervical point, lingual contact point, labial and lingual curvatures, point of labial and lingual free edge).

We focused on studying four values:

\begin{tabular}{|l|l|}
\hline S/V & $\begin{array}{l}\text { Lingual labial angle: between the lingual surface }(S) \text { and the } \\
\text { labial surface }(V)\end{array}$ \\
\hline S/AOP & $\begin{array}{l}\text { Guidance slope: slope between the lingual surface (S) and the } \\
\text { reference plane (PAO) }\end{array}$ \\
\hline VIAOP & $\begin{array}{l}\text { Labial angle: slope between the labial surface (V) and the refe- } \\
\text { rence plane (PAO) }\end{array}$ \\
\hline S/CA & $\begin{array}{l}\text { Lingual-Axial surface angle: slope between the lingual surface } \\
\text { (S) and the coronal axis (CA) }\end{array}$ \\
\hline
\end{tabular}

We evaluated these values in relation to the Frankfurt plane because the fork is parallel to the lateral arms of the face bow. To facilitate comparison of the measure- ments with other published studies, we added a corrective angle of $7^{\circ}$ to relate them to the Axial-orbital plan, which is the one most commonly utilised.

\section{3 - REPRODUCIBILITY TEST AND STATISTICAL METHODS}

Schaded validated the silicone core technique for measuring dental morphologies in 199920, using a 3D digitalizer to achieve a precision level of 0.1 to $0.15 \mathrm{~mm}$ and 0.05 to 1.6 degrees.

\begin{tabular}{|c|c|c|c|c|c|c|c|c|c|}
\hline & $\begin{array}{c}\text { Slope } \\
\text { S2/AOP }\end{array}$ & $\begin{array}{c}\text { Slope } \\
\text { S1/AOP }\end{array}$ & $\begin{array}{c}\text { Slope } \\
\text { S/AOP }\end{array}$ & $\begin{array}{c}\text { Slope } \\
\text { S/CA }\end{array}$ & $\begin{array}{c}\text { Slope } \\
\text { V/S }\end{array}$ & $\begin{array}{c}\text { Slope } \\
\text { V2/S2 }\end{array}$ & $\begin{array}{c}\text { Slope } \\
\text { V2 }\end{array}$ & $\begin{array}{c}\text { Slope } \\
\text { V1 }\end{array}$ & $\begin{array}{c}\text { Slope } \\
\text { V-AOP }\end{array}$ \\
\hline Average & 49.42 & 37.27 & 46.98 & 19.619 & 37.832 & 38.802 & 88.143 & 79.522 & 84.84 \\
\hline $\begin{array}{l}\text { Standard } \\
\text { deviation }\end{array}$ & 1.809 & 2.415 & 0.66 & 0.667 & 0.952 & 1.63 & 0.998 & 1.113 & 0.674 \\
\hline $\begin{array}{l}\text { Coefficient } \\
\text { of variation }\end{array}$ & 0.03660461 & 0.06479742 & 0.01404853 & 0.03399766 & 0.0251639 & 0.04200814 & 0.01133251 & 0.0139961 & 0.007944 \\
\hline $\begin{array}{c}\text { Coefficient of } \\
\text { variation (\%) }\end{array}$ & 3.66046135 & 6.47974242 & 1.40485313 & 3.39976553 & 2.5163882 & 4.20081439 & 1.132251 & 1.3996127 & 0.794437 \\
\hline
\end{tabular}

Table I

Reproducibility test. 
To test the reproducibility of the acquisition software, the same operator repeated computer input for the same section of a central incisor. The low coefficients of variation in these measurements (with a mean error of $3 \%$ ) indicate that this measurement can be considered to be reproducible and accurate (table I).

\section{4 - RESULTS}

The quantification of angles ( $\mathrm{S} N$, $\mathrm{S} / \mathrm{RP}, \mathrm{V} / \mathrm{RP}$ and S/CA) performed on our sample did not show any significant difference between men and women. This allowed us to group them in a homogeneous series of 49 subjects. But we used only the right hand side because of slightly signifi-
The descriptive statistical study (Stata $8.0^{\circledR}$ software) deals with four angular values characterising crown morphology. We used the t-test to compare the means of the continuous numerical variables, the chi ${ }^{2}$ test to compare the nominal or qualitative variables, and the correlation test for the links between quantitative variables. The significance threshold $\alpha$ was set at $5 \%$.

cant differences between the two sides.

For each case, we analysed the central and proximal sections. Considering the low significance of the differences, we used only the proximal sections for this study because they were closer to the functional zone (tables II, III, IV and V).

\begin{tabular}{|l|c|c|c|}
\hline & N & m & sd \\
\hline Lingual surface / coronal axis (S-CA) & 49 & 17.78 & 2.66 \\
\hline Lingual-labial angle (V-S) & 49 & 37.97 & 5.23 \\
\hline Lingual angle / Reference plane (S-RP) & 49 & 57.29 & 8.69 \\
\hline Labial angle / Reference plane (V-RP) & 49 & 88.83 & 7.9 \\
\hline
\end{tabular}

Table /I

Right central incisor: proximal section ( $N$ : number of subjects, m: mean value in degrees, sd: standard deviation).

\begin{tabular}{|l|c|c|c|}
\hline & N & m & sd \\
\hline Lingual surface / coronal axis (S-CA) & 49 & 29.29 & 4.07 \\
\hline Lingual-labial angle (V-S) & 49 & 55.93 & 6.89 \\
\hline Lingual angle / Reference plane (S-RP) & 49 & 47.43 & 10.33 \\
\hline Labial angle / Reference plane (V-RP) & 49 & 93.18 & 8 \\
\hline
\end{tabular}

Table III

Right canine: proximal section ( $N$ : number of subjects, $m$ : mean value in degrees, sd: standard deviation). 


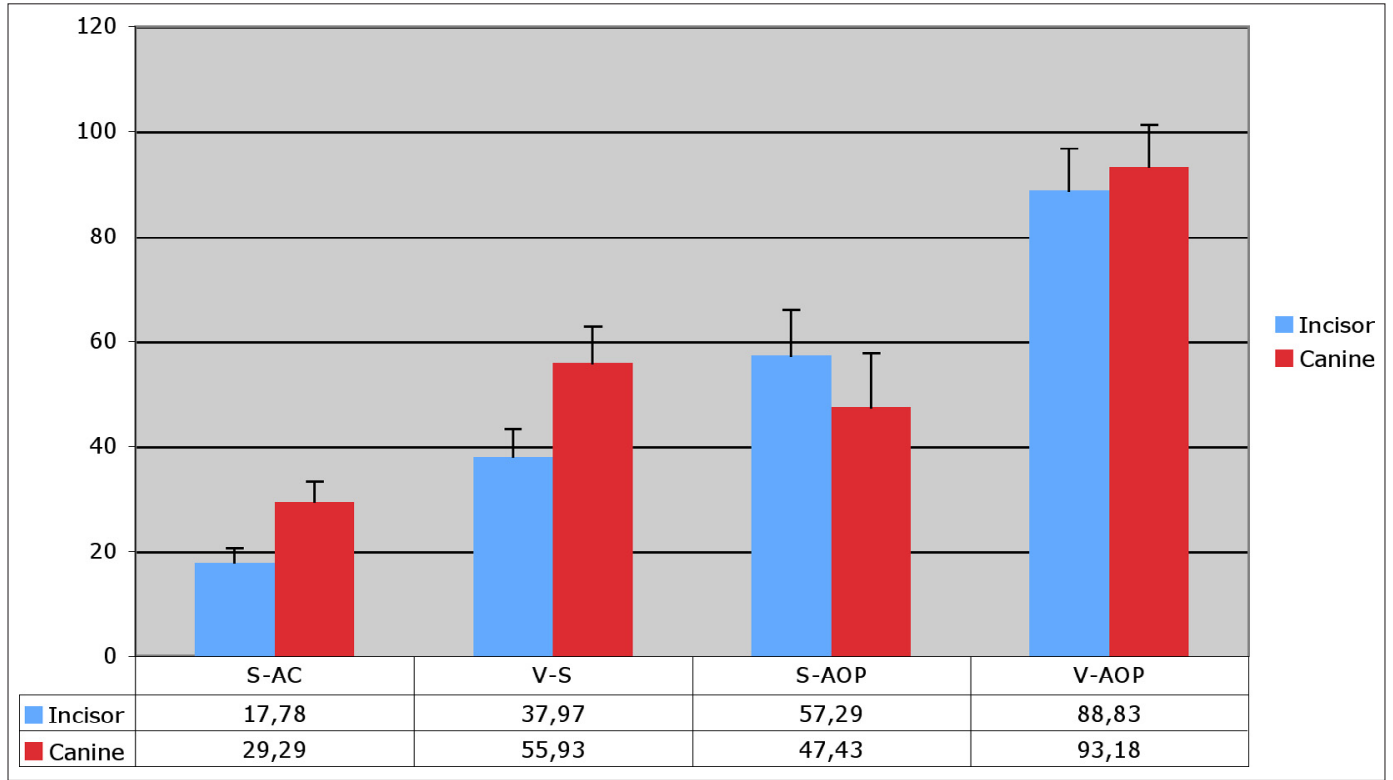

Table IV

Comparison of mean values between canine (red) and central incisor (blue): slopes of lingual coronal axis (S-CA) and labial (V) surfaces on the reference plane (RP) or the main coronal axis (CA).

The correlation study (table V) between the two parametric variables showed that there is a high $r$ coefficient (approx. 0.8) between the maxil- lary central incisor's labial and lingual surfaces but a very low one for the canine's buccal and lingual surfaces ( $r$ coefficient 0.01 ).

\begin{tabular}{|c|c|c|c|}
\hline Tooth & Observation & Correlation factor & $p$ \\
\hline 11 & 49 & 0.8 & 0.000 \\
\hline 13 & 49 & -0.093 & 0.51 \\
\hline
\end{tabular}

Table $\mathrm{V}$

Correlation between the labial angle on the Reference plane $(V-R P)$ and the lingual angle on the Reference plane (S-RP).

\section{5 - DISCUSSION}

Despite the limitations of this study, in relatively low sample size and single geographic location of the population, it nevertheless provides original biometric data that quantifies the biometric variability of maxillary anterior teeth.

\section{5 - 1 - Guidance slope in the AOP}

Relative to the Axial-orbital plane, the values of the guidance slope tilt (S) on the lingual surface (S/AOP) fall distinctly (approx. $10^{\circ}$ ) between the 


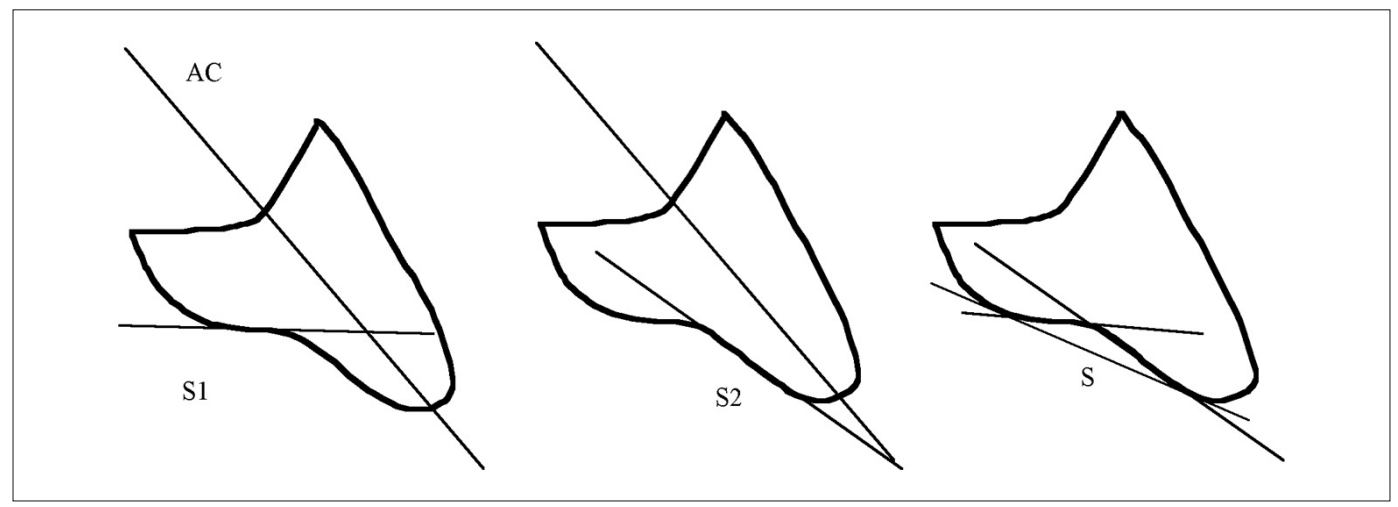

Figure 11

Different angles measured by Slavicek in 1983: S1: Cingular plane, S2: 2/3 occlusal, S: mean lingual slope.

central incisor $\left(\mathbf{5 7 ^ { \circ } )}\right.$ and the canine $\left(47^{\circ}\right)$.

Slavicek, in $1983^{23}$ was the first to suggest this analytical method, with a study of the upper central incisor involving more than 1000 cases. His description of the lingual surface (fig. $11)$ includes 3 measurement planes: S1 (1/3 cingular), S2 (1/3 occlusal) and $\mathrm{S}$ (median plane). The measurements revealed an incisor slope (S2) of about $60^{\circ}$, confirmed by Orthlieb in $1990^{16}$ with an angle of $61.35^{\circ} \quad(n=229$, $\mathrm{sd}=12.4$ ).

Kulmer also confirmed these results in 1999 on 34 young Austrians $^{13}$. Celar reports slightly lower values for a Japanese population of 82 young subjects: central incisor: 51.5 (sd: 11.4), canine 44.2: (sd: 10.2$)^{2}$. Hobo ${ }^{7}$ found the same level of dispersion for the incisor slope.

The mean values we obtained in our study therefore confirmed the previous work. They underline the need to achieve a canine slope of around $45^{\circ}$, about $10^{\circ}$ less than the incisor slope.

\section{5 - 2 - Labial}

\section{surface slope in the AOP}

The mean slopes found are close to a right angle.

Comparison between the incisor and the canine shows that the buccal surface of the canine is slightly tilted buccally $\left(94^{\circ}\right)$ whereas the incisor's inclination $\left(88^{\circ}\right)$ is more lingual. The curvature of the canine is slightly more accentuated.

\section{5 - 3 - Angle of slope on lingual / coronal axis / labial surface}

We start from the principle that the coronal axis in humans is similar to the crown-root axis. The angle between the labial surface and the coronal axis does not show any particular variations. It is lingually, on the hidden surface of maxillary anterior teeth, that morphological variability can be found. 
The angle between the lingual slope and the coronal axis (S/CA) increases between the central incisor $\left(18^{\circ}\right)$ and the canine $\left(\mathbf{2 9}^{\circ}\right)$. Slavicek 23 reports a mean value of $23^{\circ}$ for S/CA for the canine. This underscores the thicker labio-lingual shape of the canine with its highly convex lingual surface. It seems to us important to emphasise the variability of this angle in orthodontics. While the angle between the labial surface and the lingual surface (V/S) has a standard deviation of $7^{\circ}$ for the canine, it is only $5^{\circ}$ for the incisor. Slavicek ${ }^{23}$ reports standard deviations of $10^{\circ}$.

Therefore, by using the vertical orientation of the labial surface of the canine as a reference, the guidance slopes may vary by $15^{\circ}$ to $20^{\circ}$. Functionally speaking, this variation could be important when lateral excur- sion operates to obtain minimal disocclusion posterior to the canine without interference. It may be noted that the lack of correlation between the labial and lingual slopes of the canine shows that by observing only the labial surface slope an orthodontists cannot discern any information about the canine guidance slope.

\section{5 - 4 - Evolution and comparative anatomy}

At the anthropology laboratory in the Marseille Faculty of Medicine, a comparative anatomy study of anterior teeth in a dry skull was carried out using an identical protocol. In 2001, K. Illouz compared the incisors of 10 large ape skulls, 27 prehistoric men, 15 medieval men, and 35 modern subjects $^{9}$ in vivo. In 2003, F. Bukiet compared the canines of 10 large apes, 14

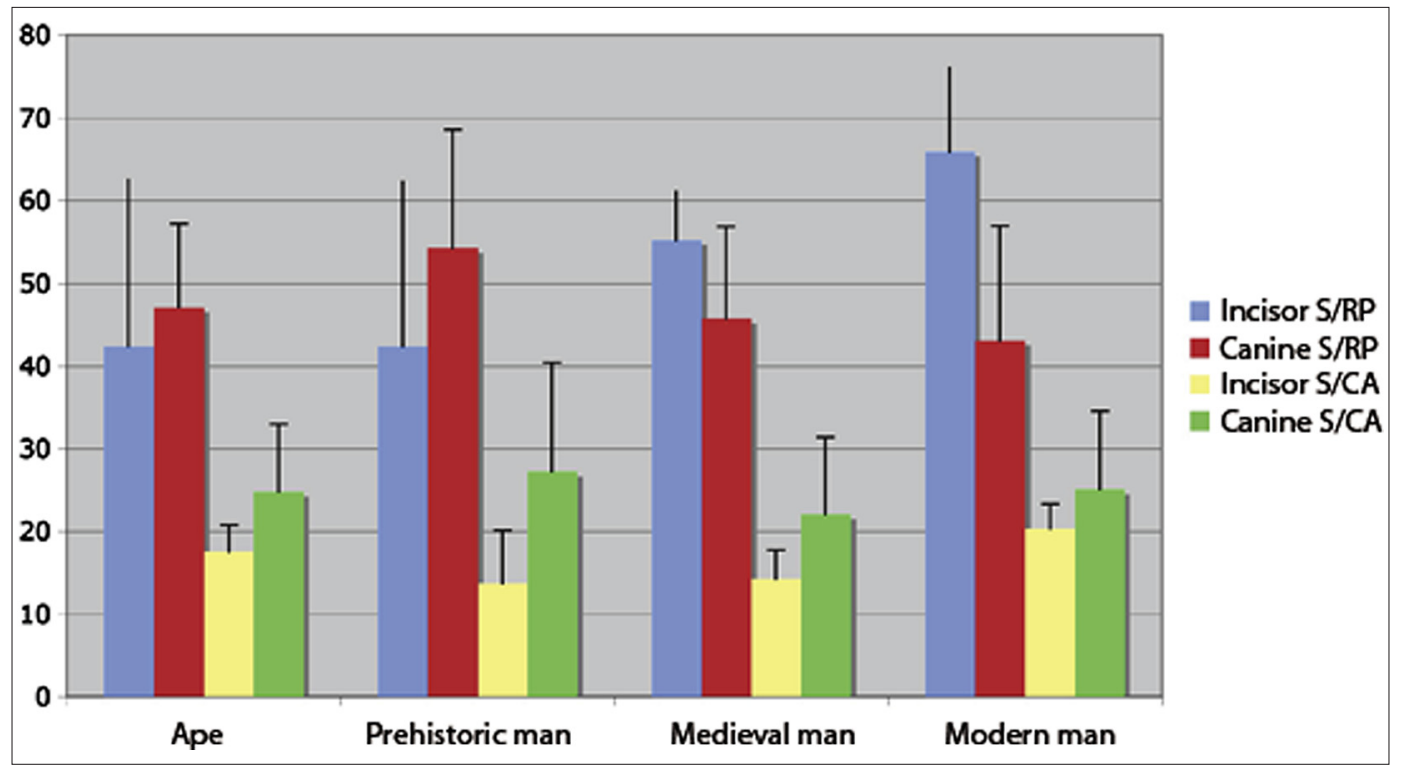

Table VI

Comparative anatomy: comparison of incisors and canines (S/RP: lingual slope on reference plane, S/CA: guidance slope on coronal axis). 
prehistoric men, 40 medieval men, and 21 modern subjects ${ }^{1}$ in vivo.

Table VI summarises these studies and leads to several observations.

- The lingual slope of the incisor is distinctly increasing whereas the lingual slope of the canine is decreasing.

- Verticalisation of the incisors is coherent with the increase in incisal over-bite.

- Reduction of the lingual slope of the canine.

\section{6 - CONCLUSION}

Our study provides biometric data about maxillary canines and central incisors in modern humans. These data are intended to be used for prosthetic or orthodontic treatment.

This work confirms the thicker, more curved configuration of the maxillary canine compared to the central incisor and also its shallower lingual slope. The mean values that we report in our study underline the benefit of targeting a canine slope of around $45^{\circ}$, which is about $10^{\circ}$ less than the incisor slope. On the other hand, it is logical to think that our treatments must not lead to:

- a canine slope of more than $60^{\circ}$;

- a canine slope which is steeper than the incisor slope.

Although distinct stability is noted in labial and buccal morphology, there is variation in lingual morphology, particularly of the canine.

These variations in a functionally critical zone are great enough to affect the orthodontist's choice of pretorqued, pre-angulated brackets. It is conceivable that as studies in this
- The angles between the lingual slope and the coronal slope (S/CA) are virtually constant, which indicates very few morphological modifications.

- The values for current populations harmonise with the results of the study presented.

- Because of the size of the samples, it is difficult to attribute the slight differences noted to an ethnic variation between the south of France and Lebanon.

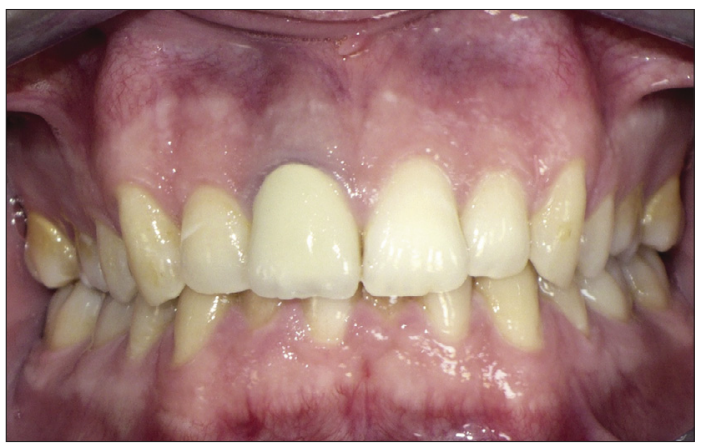

Figure 12

Example of the close of orthodontic treatment: the maxillary canines, with their strong lingual inclination side, have slopes that are steeper than those of the incisors. This is the opposite of what should have been obtained.

area flourish, that 3 or 4 classes of labio-lingual angles may be defined to aid in such a selection.

The limitations of this work require that our conclusions be used only as hypotheses that deserve future in depth investigations with larger sample sizes and the introduction ethnic variations as well as typological categories. 


\section{BIBLIOGRAPHY}

1. Bukiet F. Etude biométrique de la canine maxillaire permanente les hominidés. Mémoire de D.E.A Laboratoire d'Anthropologie "Quaternaire», Faculté de médecine. Marseille : Université de la Méditerranée, 2003.

2. Celar A, Kubota M, Akimoto S, Sato S, Slavicek R, Hennerbichler E. Inclines of occlusal guidance,wear facets, and hinge axis path considering sequential guidance with canine dominance. Bulletin of Kanagawa dental college 1997;25(1):3-9.

3. Celenza FV. An analysis of articulators. Dent Clin North Am 1979;23:305-26.

4. Delattre A, Fenart R. Otospongiosis and cranio-labyrinthine rotation. J C R Hebd Seances Acad Sci 1960 Oct 10;251:1563-4.

5. Espinosa de la Sierra R. Development of organic occlusion. J Gnathology 1985;4:87-115.

6. Feuillerat $C$, Simon J, Orthlieb JD. Morphologie fonctionnelle des incisives maxillaires. Cahiers Prothèse 1988;63:83-97.

7. Hobo, 1997.

8. Horris WH MC. The importance of anterior teeth. J Gnathology 1982;1:19-36.

9. Illouz K. Anatomie comparée de l'incisive médiale maxillaire chez les Hominidés. Mémoire de D.E.A Laboratoire d'Anthropologie "Quaternaire», Faculté de médecine. Marseille : Univ de la Méditerranée, 2001.

10. Ingervall B. Tooth contacts on the functionnal and non functionnal side in children and youngs adults. Arch Oral Biol 1972;17:191-5.

11. Kiezer JA, Groeneveld HT. The reliability of human odontometric data. J Dent Assoc S Afr 1991;46(5):267-70.

12. Kubein-Meesenburg $D$ et al. Individual reconstruction of palatal concavities. J Prosth Dent 1988;60(6):662-72.

13. Kulmer S, Ruzicka B, Niederwanger A, Moshen I. Incline and length of guiding elements in untreated naturally grown dentition. J Oral Rehabil 1999;26(8):650-60.

14. Lacroix P. Le surplomb et le recouvrement incisif et canin dans l'évolution du guide antérieur. Mémoire de D.E.A «Quaternaire», Faculté de médecine. Marseille : Univ de la Méditerranée, 1998.

15. Lexique d'occlusodontologie, College national d'occlusodontologie, Quintessence, 2001.

16. Orthlieb JD. Diagnostic occluso-céphalométrique assisté par ordinateur (Occluso-cephalometric computerised diagnosis). Doctorat d'Université. Marseille : Univ de la Méditerranée, 1990.

17. Orthlieb JD, El Zoghby A, Kordi M, Perez C. La fonction de guidage : un modèle biomécanique pour un concept thérapeutique. Cahiers Prothèse 2004;128:43-54.

18. Pitchford JH. A reevaluation of the axis-orbital plane and the use of orbital in a face bow transfer record. J Prosthet Dent 1991 Sep;66(3):349-55.

19. Rinchuse $D$, Kandasamy $S$ and Sciote J. A contemporary and evidence-based view of canine protected occlusion. Am J Orthod Dentofacial Orthop 2007;132(1):90-102.

20. Schaden G, Kulmer S, Dumfahrt H. Untersuchung der individuellen frontzahnfuhrung ein methodenvergleich. IOK 1995;27(1):7-13.

21. Seligman DA, Pullinger AG. Analysis of occlusal variables dental attrition, and age for distinguishing healthy controls from female patients with intracapsular temporomandibular disorders. J Prosthet Dent 2000;84(1):114-5.

22. Shavell HM. Amalgocclusion: de la creation artistique d'une anatomie dentaire fonctionnelle grâce à l'amalgame d'argent. Réalités cliniques 1993;4:119-32. 
23. Slavicek R. Les principes de l'occlusion. Rev Orthop Dento Faciale 1983;17:449-90,533-43.

24. Valentin.C. Le guidage antérieur en denture naturelle. C.N.O. zes journées du collège national d'occlusodontologie. Reims, 14-15 mars 1986.

25. Williamson EH, Lundquist DO. Anterior guidance: its effect on EMG activity of the temporal and masseter muscles. J Prosthet Dent 1983;49:816-22. 